\title{
Phototransposition chemistry of pyridine and substituted pyridines in the vapor phase
}

\author{
James W. Pavlik*a and Naod Kebede ${ }^{b}$ \\ ${ }^{a}$ Department of Chemistry and Biochemistry, Worcester Polytechnic Institute, \\ Worcester, Massachusetts, 01609, USA \\ ${ }^{b}$ Department of Chemistry, Edinboro University, \\ Edinboro, Pennsylvania, 16444, USA
}

Email:jwpavlik@wpi.edu

\section{Abstract}

Irradiation of the six isomeric dimethylpyridines or six isomeric trideuteropyridines in the vapor phase at 254 $\mathrm{nm}$ leads to two triads of three interconverting compounds. Monosubstituted pyridines undergo phototransposition in the vapor phase at $254 \mathrm{~nm}$ to yield one triad of the three interconverting compounds. Thus the three isomeric methylpyridines, the three isomeric cyanopyridines, and the three isomeric tetradeuteropyridines each undergo phototransposition to three interconverting compounds.

These ring transposition reaction take place by photo-ring closure followed by N-migration around the five sides of the cyclopentadienyl and rearomatization. This mechanism allows nitrogen to insert between each pair of ring atoms. The mechanism predicts the observe regioselectivity of the transposition reactions.

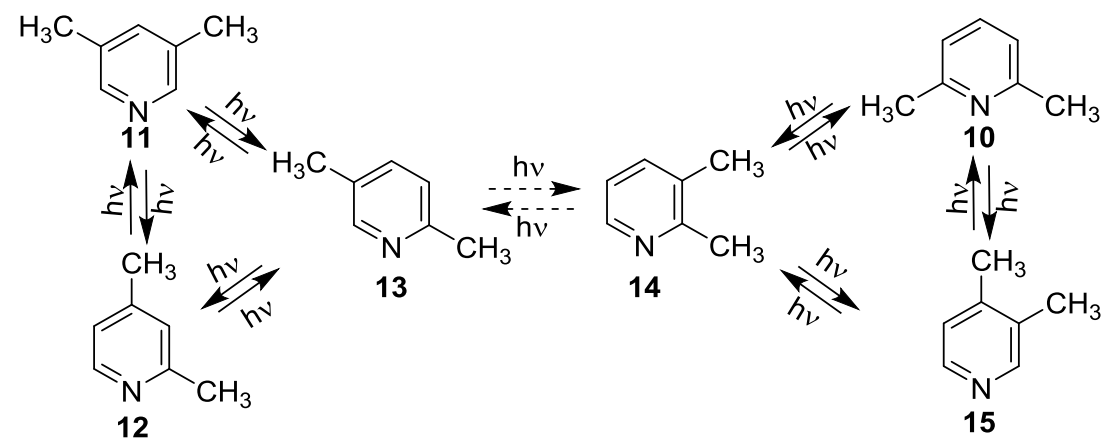

Keywords: Pyridine, substituted pyridines, phototransposition, irradiation, vapor phase, photoisomerization 


\section{Table of Contents}

1. Introduction

2. Discussion

2.1. Early work

2.2. Dimethylpyridines

2.3. Monosubstituted pyridines: methyl and cyanopyridines

2.4. Deuterated pyridines

2.5. Mechanistic discussion

3. Conclusions

References

\section{Introduction}

Pyridine is a fundamentally important ring system in organic chemistry. Its thermal properties are well-known and are rich and varied. Its photochemical properties are quite different. Like other heteroaromatic compounds, pyridine has two excite states: $\left(n \rightarrow \pi^{*}\right)$ and $\left(\pi \rightarrow \pi^{*}\right)$. Since these are electronic isomers, their chemistry is expected to be unique. Furthermore, the reactivity very often is dependent on the phase of the compound. Although a previous review dealt mainly with photochemistry in the solution phase, ${ }^{1}$ this review deals specifically with photochemical reaction in the vapor phase.

\section{Discussion}

\subsection{Early work}

In 1966 Pascual and Tuazon reported ${ }^{2}$ that irradiation of 2-methylpyridine 1 in the vapor phase for 72 hours with a $\mathrm{Hg}$ arc lamp resulted in the formation of 4-methylpyridine 2, 2,4-dimethylpyridine 3, and a large amount of polymer (Scheme 1). Irradiation of 4-methylpyridine $\mathbf{2}$ resulted in 2-methylpyrdine 1, pyridine 4, and small amount of polymer but no dimethylpyridines (Scheme 2).

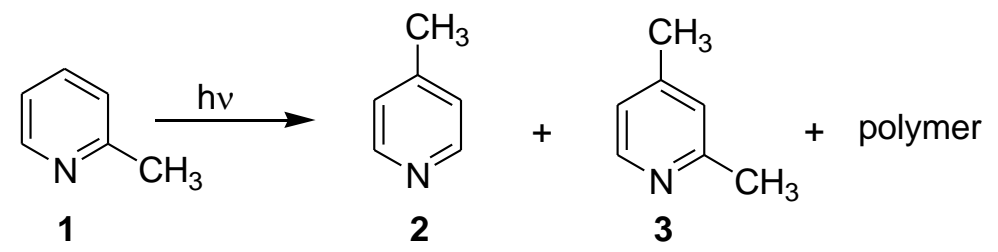

Scheme 1. Irradiation of 2-methylpyridine 1.

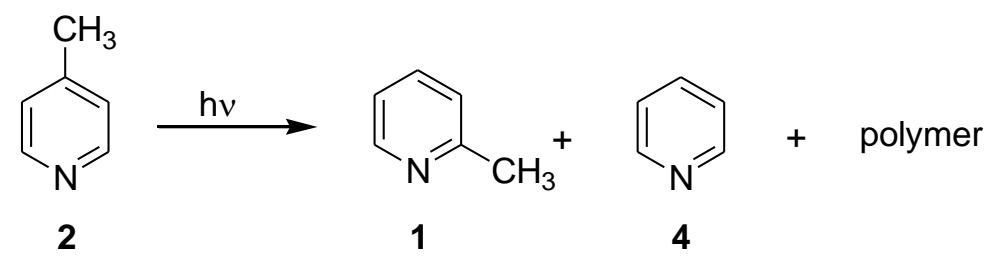

Scheme 2. Irradiation of 4-methylpyridine 2. 
They suggested the interconversion of $\mathbf{1}$ and $\mathbf{2}$ may occur via a radical methylation-demethylation process. Linnel and Noyes reported ${ }^{3,4}$ that pyridine 4 vapor undergoes decomposition when irradiated at 254 $\mathrm{nm}$ with no identifiable product being formed. At shorter wavelength, however, gaseous products were formed. A qualitative study using flash photolysis identified the products as acetylene $\mathbf{5}$ and $\mathrm{H}-\mathrm{CN} \mathbf{6}$.

These products were proposed to be formed by way of the Dewar-pyridine 7 intermediate. Loss of H-CN 6 was proposed to yield cyclobutadiene 8. Photolytic ring opening of $\mathbf{8}$ then gave rise to acetylene $\mathbf{5}$ (Scheme 3).

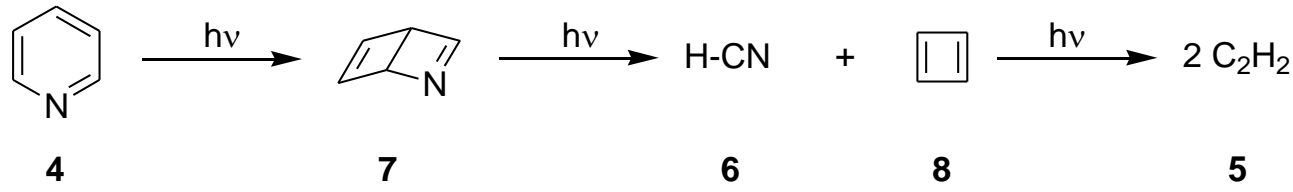

Scheme 3. Irradiation of pyridine at $\lambda<254 \mathrm{~nm}$.

Roebke $^{5}$ also studied the photochemistry of 2-methylpyridine 1 . In the gas phase, irradiation in the $n \rightarrow \pi^{*}(0,0)$ transition region ( $288 \mathrm{~nm}$ ) did not yield any detectable photoproduct. However, when the irradiation was carried out in the $\pi \rightarrow \pi^{*}$ region $(238-266 \mathrm{~nm}$ ), 3-methylpyridine 9 and 4-methylpyridine 2 were formed in a 10:1 ratio (Scheme 4). The yield of these products increased from $\phi=9.0 \times 10^{-5}$ to $5.1 \times 10^{-4}$ with increase in the energy of light from 266 to $238 \mathrm{~nm}$. This led to the suggestion that both electronic and vibrational excitation have important roles in the photoreaction. Addition of $\mathrm{O}_{2}$ or cis-2-butene, know triplet quenchers, lowered the yield of the isomerization products. Thus, Roebke suggested that the involvement of a triplet state in the isomerization could not be ruled out.

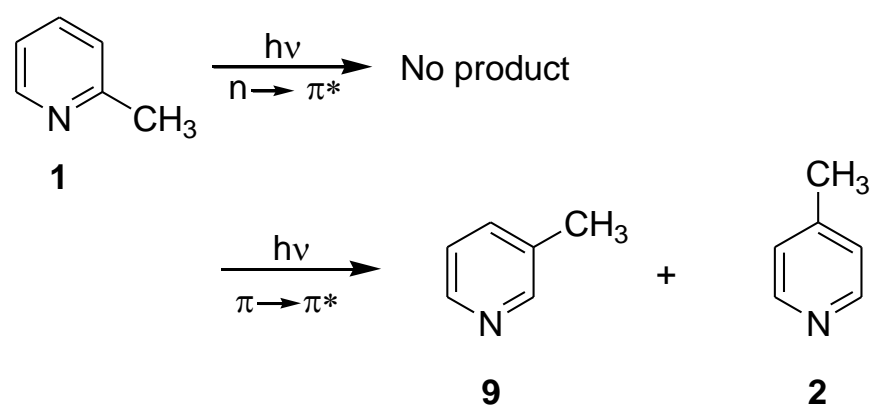

Scheme 4. $n \rightarrow \pi^{*}$ and $\pi \rightarrow \pi^{*}$ irradiation of 2-methylpyridine 1 .

However, this statement contradicts the observation that the quantum yield of triplet formation is higher $\left(\phi_{T}=0.21\right)$ from the $\left(n, \pi^{*}\right)$ state than from the $\left(\pi, \pi^{*}\right)$ state $\left(\phi_{T}=0.031\right)$ by a factor of 7 . It has been shown by the author ${ }^{4}$ that no isomerization took place when the irradiation was carried out in the $\left(n \rightarrow \pi^{*}\right)$ region. Thus, the involvement of a triplet state in the isomerization process is doubtful. It is more likely that added $\mathrm{O}_{2}$ or cis2-butene acted as a vibrational quencher.

According to Roebke ${ }^{5}$, a mechanism involving an azabenzvalene would not allow for the photoisomerization of 2-methylpyridine $\mathbf{1}$ to 3-methylpyridine $\mathbf{9}$ and 4-methylpyridine $\mathbf{2}$. Indeed, from the possible azabenzvalenes from 2-methylpyridine 1 only 3-methylpyridine $\mathbf{9}$ can be formed.

Roebke $^{5}$ suggested a mechanism involving an azaprismane intermediate formed from a Dewar-pyridine as a reasonable reaction pathway for the observed rearrangement. The conversion of 2-methylpyridine 1 to 3methylpyridine 9 and 4-methylpyridine $\mathbf{2}$ is shown in Schemes 5 and 6. Thus Scheme 5 shows 2,5-bonding in 1 
resulting in the formation of Dewar-pyridine DP-1-2,5. Subsequent [2+2] cycloaddition of DP-1-2,5 would give azaprismane AP-1. AP-1 can then undergoing opening by three distinct bond cleavage pathways resulting in the formation pf Dewar-pyridines DP-1-2,5, DP-1-N,4, and DP-9-2,5. Rearomatization of DP-1-N,4 and DP-92,5 would yield the starting material 2-methylpyridine $\mathbf{1}$ and 3-methylpyridine 9, one of the observed products.

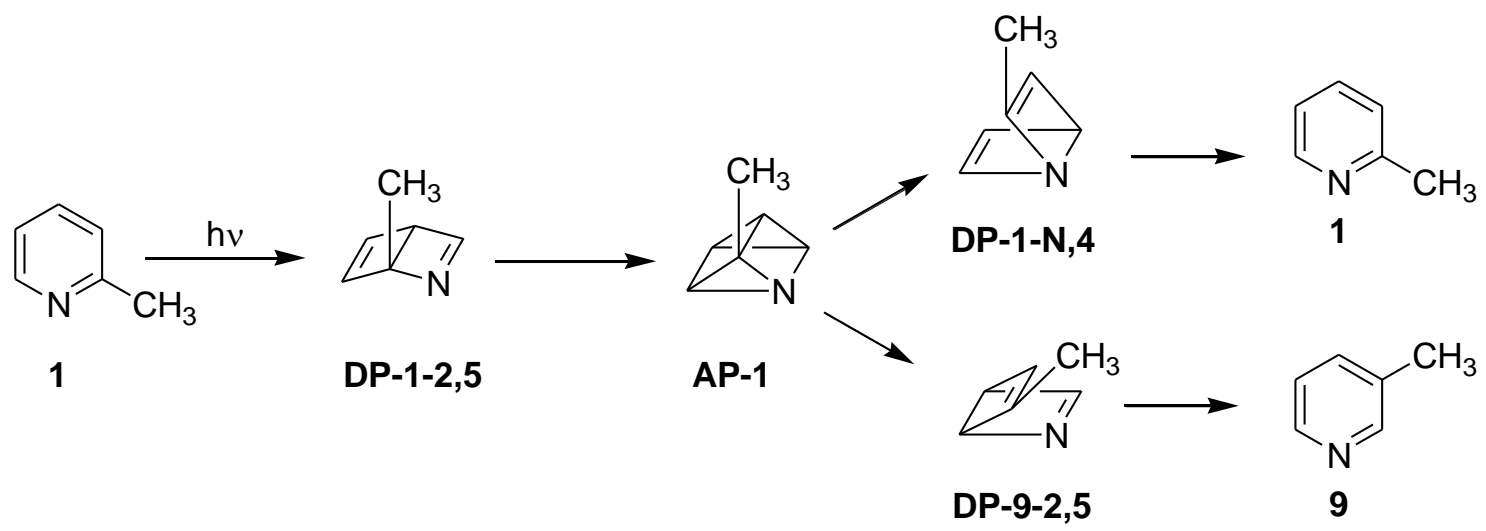

Scheme 5. Roebke's mechanism for the conversion of $\mathbf{1} \rightarrow \mathbf{9}$.

Alternatively, as shown in Scheme 6, Dewar-pyridine DP-1-3,6 formed by 3,6-bridging in 1 and azaprismane AP-2 formed by [2+2] cycloaddition. Bond cleavage and rearomatization would yield that starting pyridine 1 and 4-methylpyridine 2, the other observed product. Thus the mechanism suggested by Roebke $^{5}$ requires the involvement of both methyl substituted Dewar-pyridines DP-1-2,5 and DP-1-3,6 to account for the observed products.

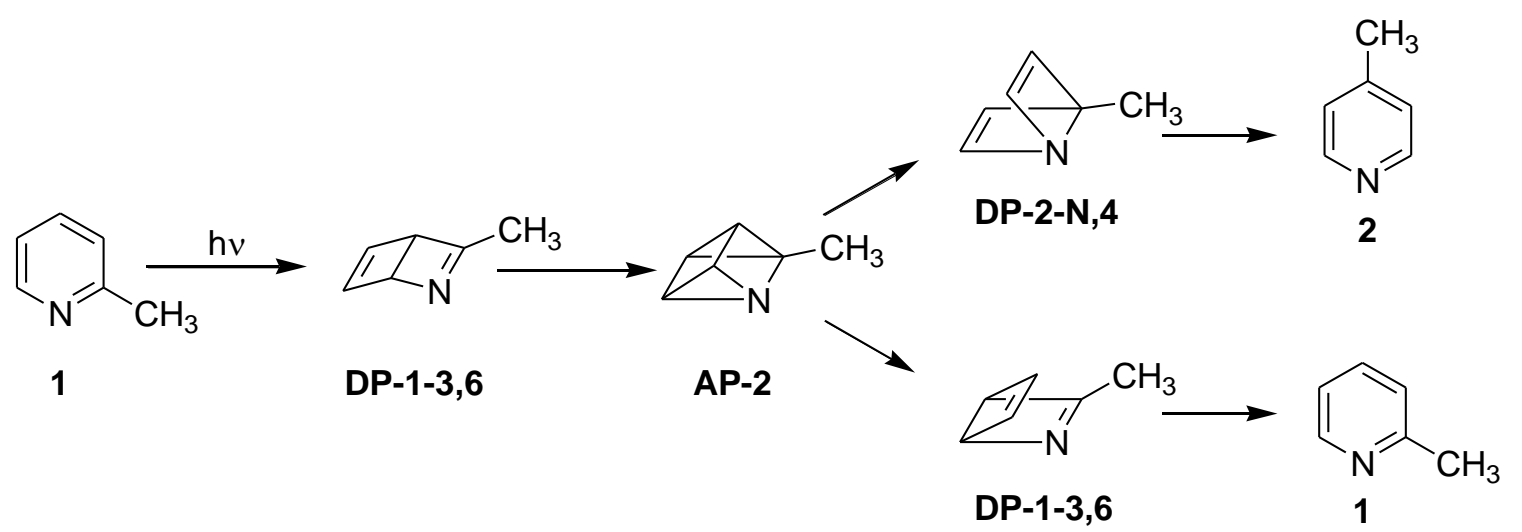

Scheme 6 . Roebke's mechanism for the conversion of $\mathbf{1} \rightarrow \mathbf{2}$.

Although not considered by Roebke, a third Dewar-pyridine DP-1-N,4, formed by 1,4-bonding in 2methylpyridine $\mathbf{1}$ is possible. DP-1-N,4 would yield azaprismane AP-3 by [2+2] cycloaddition. As shown in Scheme 7, bond breaking and rearomatization would yield the starting pyridine $\mathbf{1}$ and 3-methylpyridine $\mathbf{9}$, one of the observed products. 


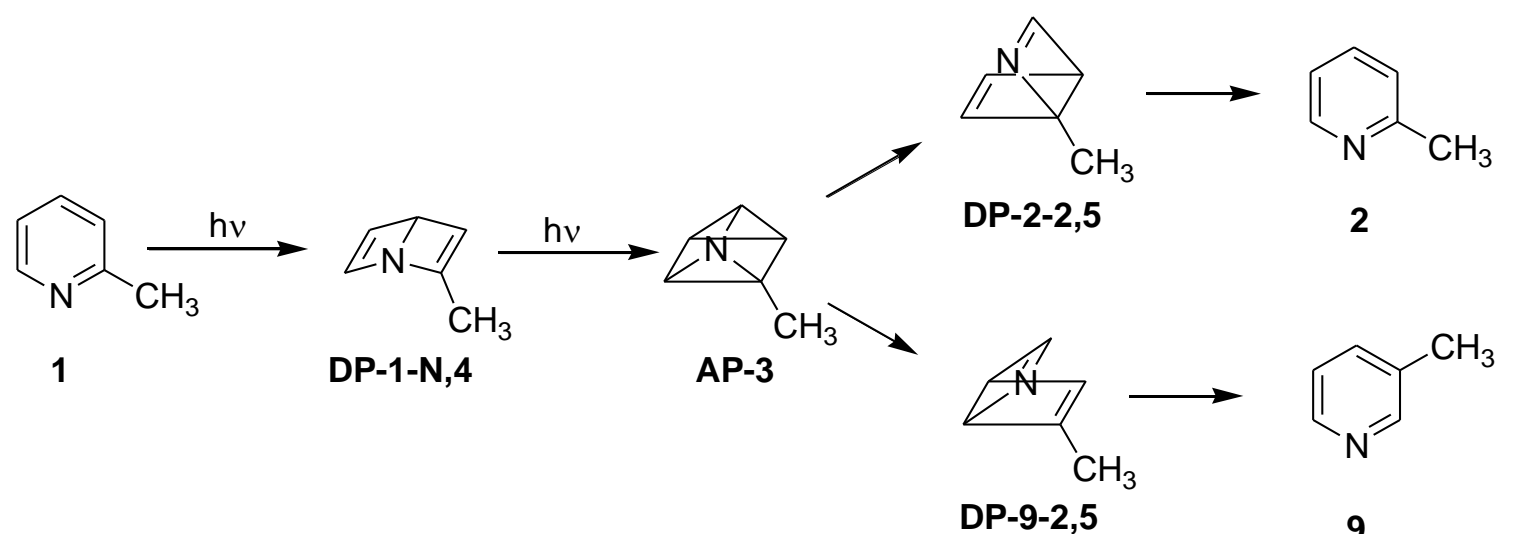

Scheme 7. An additional mechanism for the conversion of $1 \rightarrow \mathbf{9}$.

The photochemistry of methylpyridines and dimethylpyridines in the vapor phase was reported in a communication by Caplain and Lablache-Combier. ${ }^{6}$ Unlike the report of Roebke, ${ }^{5}$ Caplain and LablacheCombier $^{6}$ reported that irradiation of 2-methylpyridine $\mathbf{1}$ resulted in the formation of only 4-methylpyridine $\mathbf{2}$, the minor product reported by Roebke. ${ }^{5}$

When the dimethylpyridines were irradiated in the vapor phase, these authors ${ }^{6}$ reported that they undergo photoisomerization as well as demethylation and methylation reactions. To account for the photoisomerization they reported, Caplain and Lablache-Combier suggested a ring transposition mechanism also involving azaprismane intermediates. ${ }^{6}$

A perplexing feature of the transposition mechanism shown in Scheme 8 is the selectivity required to explain the reported products. Thus, as shown in Scheme 8, the reported conversion of 2,6-dimethylpyridine 10 to 2,4-dimethylpyridine 12 requires that 10 undergoes 2,5- (or 3,6-) bonding (but not $N_{1}-C_{4}$ bonding) and regiospecific opening of the subsequently formed azaprismane via cleavage of $C_{3}-C_{4}$ and $C_{5}-C_{6}$ bonds, but not the $\mathrm{C}_{2}-\mathrm{C}_{3}$ and $\mathrm{N}_{1}-\mathrm{C}_{6}$ bonds, which would have resulted in 2,5-dimethylpyridine 13 which was not observed.

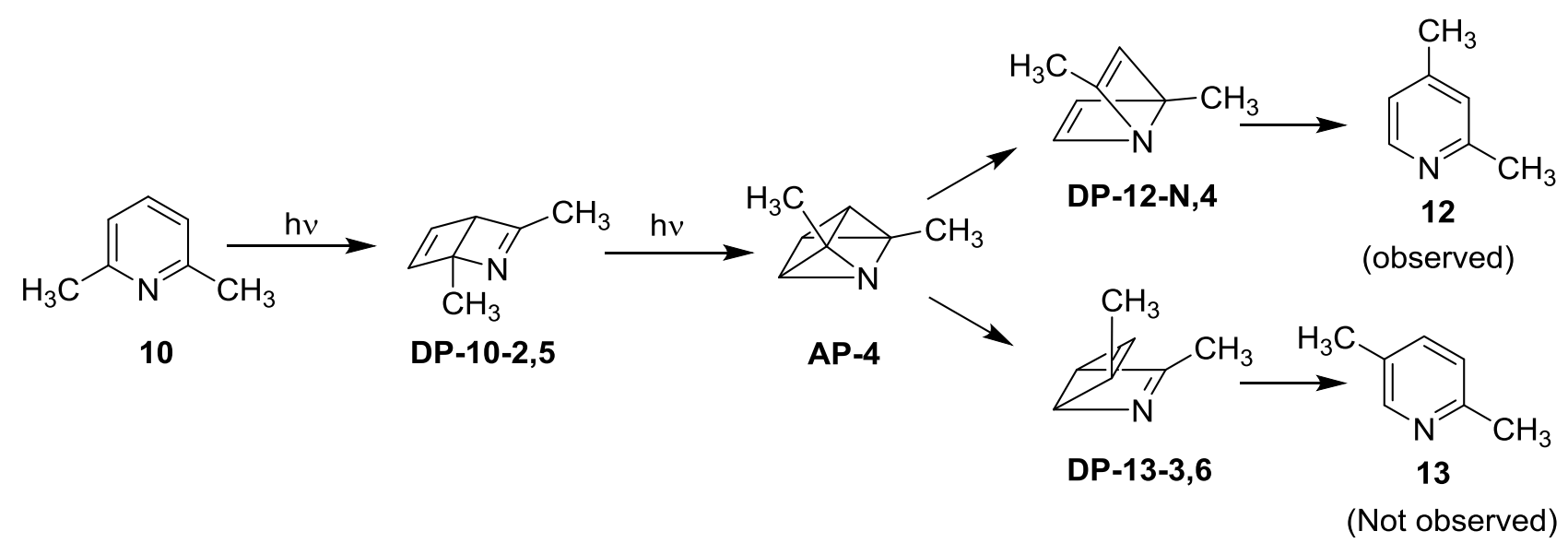

Scheme 8. Mechanism for the conversion of 2,6-dimethylpyridine 10 to 2,4-dimethylpyridine 12 as suggested by Caplain and Lablache-Combier. ${ }^{6}$ 
Furthermore, the reported conversion of 2,3-dimethylpyridine 14 to a mixture of 3,4-dimethylpyridine 15 and 2,5-dimethylpyridine 13 required (Scheme 9) initial $N_{1}-C_{4}$ bonding (but not 2,5- or 3,6-bonding) followed by azaprismane cleavage by both possible pathways.

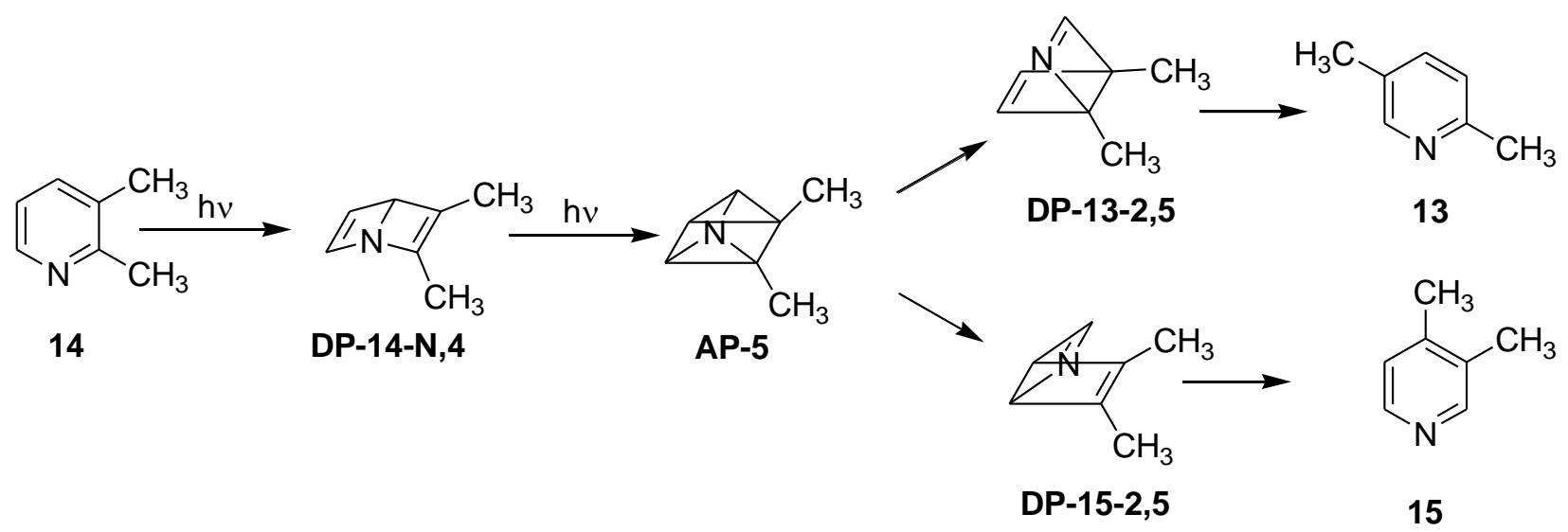

Scheme 9. Mechanism for the conversion of 2,3-dimethylpyridine 14 to 3,4-dimethylpyridine 15 and 2,5dimethylpyridine 13 as suggested by Caplain and Lablache-Combier. ${ }^{6}$

\subsection{Dimethylpyridines}

As a result of these mechanistic ambiguities, we have reinvestigated the photochemistry of the six isomeric dimethylpyridines in the vapor phase. ${ }^{8}$ To our surprize the phototransposition products we observed ${ }^{7}$ are $^{-}$ totally different that those observed by Caplain and Lablache-Combier. ${ }^{6}$

Irradiation of dimethylpyridines in the vapor phase results in the phototransposition, demethylation and methylation reactions. Experimental evidence indicate the operation of two mechanistically different phototransposition pathways. The major products are formed when irradiation is carried out in the vapor phase at $254 \mathrm{~nm}$. These products are substantially quenched upon dilution of the reactant with $\mathrm{N}_{2}$ gas and are not formed when the dimethylpyridines vapors are irradiated at $\lambda>290 \mathrm{~nm}$.

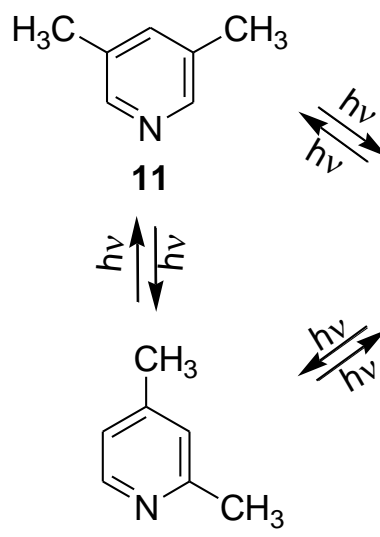

12<smiles>Cc1ccc(C)nc1</smiles>

13<smiles>Cc1cccnc1C</smiles>

14

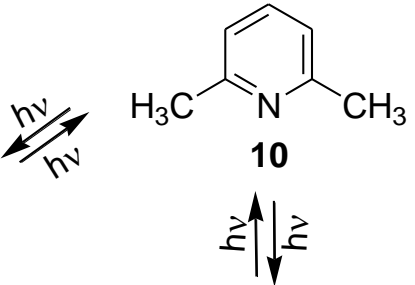

$h_{2}$<smiles>Cc1ccncc1C</smiles>

15

Scheme 10. Two photochemical triads formed upon irradiation of dimethylpyridines in the vapor phase. Reprinted with permission. ${ }^{8}$ Copyright 1999, American Chemical Society. 
A second pathway is also implicated which is enhanced by dilution with $\mathrm{N}_{2}$ and is the only pathway in operation upon irradiation at $\lambda>290 \mathrm{~nm}$. The major products can be divided into two triads, each containing three interconverting compounds as shown in Scheme 10. Inspection of the isomers of the two triads shows that the compounds of each triad differ in the position of the nitrogen atom within the skeleton of the pyridine ring.

A mechanism that allows for this selective insertion involves photo-ring closure, nitrogen migration around the sides of the cylopentenyl ring, and rearomatization. The mechanism for Triad 1 is shown in Scheme 11. Thus, ring closure of 3,5-dimethylpyridine $\mathbf{1 1}$ results in the formation of azabicylcohexenyl BC-11 shown as a diradical.

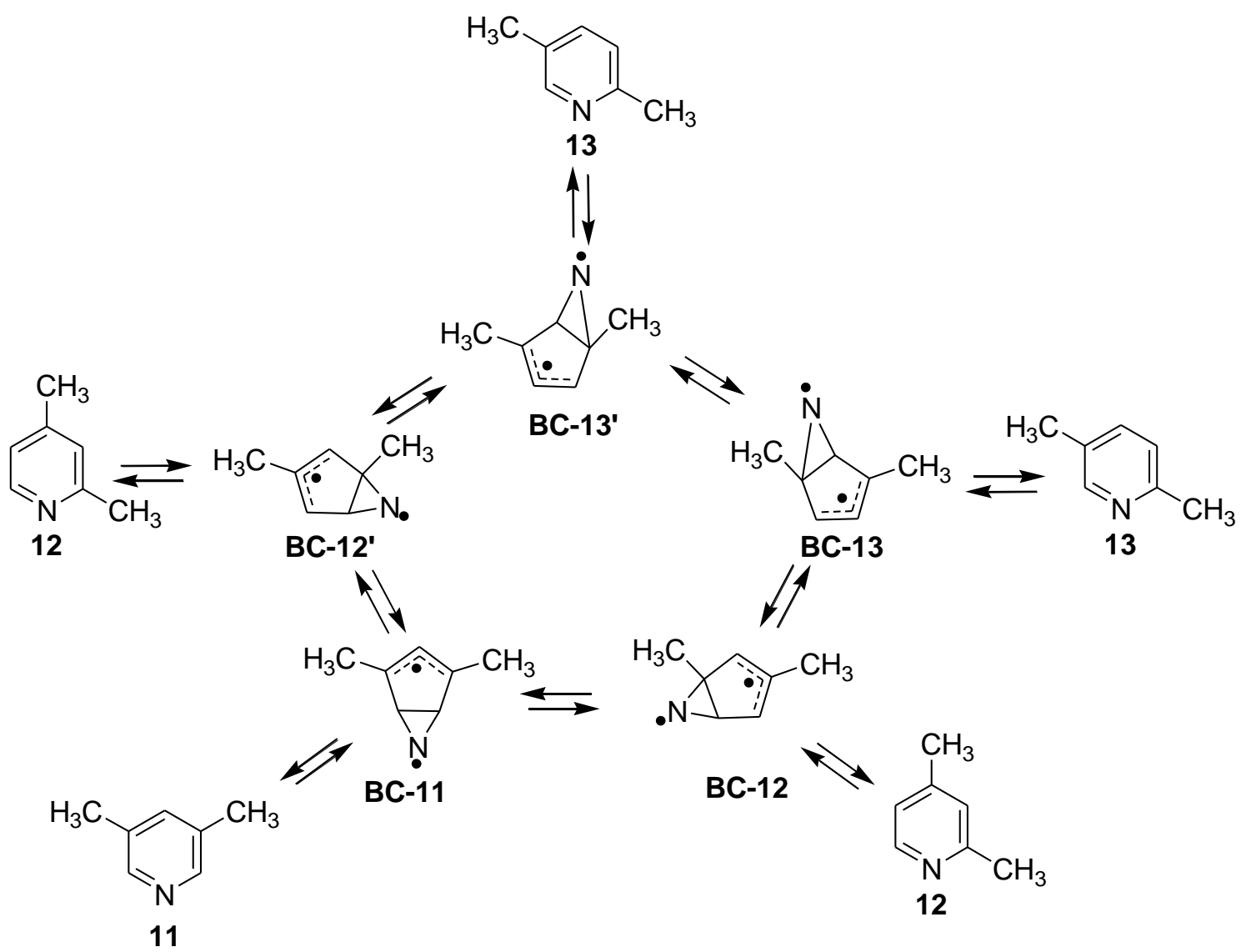

Scheme 11. Suggested mechanism for Triad-1. Reprinted with permission. ${ }^{8}$ Copyright 1999, American Chemical Society.

This structure is analogus to the bicyclic species originally named prevalene and suggested by Bryce-Smith to be the photochemically generated precursor of benzvalene. ${ }^{9}$ Sigmatropic migration of nitrogen around the 5 sided of the cyclopentenyl ring allows interconversion of BC-11 with the azabicyclohexenyl species BC-12 and BC-13 which, after rearomatization, allows the interconversion of $\mathbf{1 1}$ with $\mathbf{1 2}$ and $\mathbf{1 3}$, the other members of the triad, but not any other dimethylpyridines. A similar mechanism can be envisioned for Triad 2 and is shown in Scheme 12. 


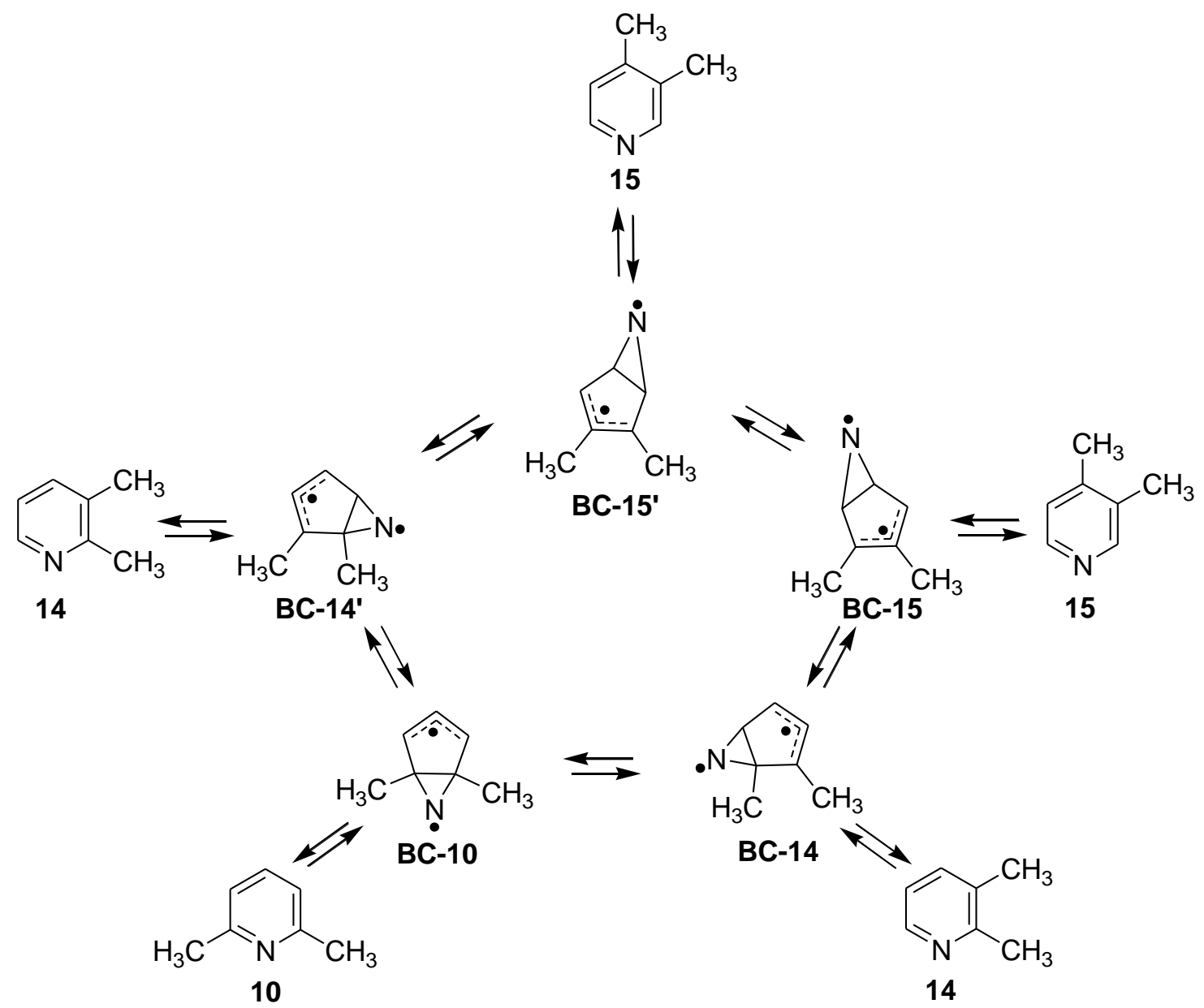

Scheme 12. Suggested mechanism for Triad-2. Reprinted with permission. ${ }^{8}$ Copyright 1999, American Chemical Society.

Although the 2,6-bonding-heteroatom migration mechanism accounts for the interconversions of the three members of each triad, it excludes the interconversion of member of Triad 1 with members of Triad 2. Experimental evidence, however, clearly shows that the two triad are connected via interconversion of 2,5dimethylpyridine 13, a member of Triad 1, and 2,3-dimethylpyridine 14, a member of Triad 2. These inter-triad interconversions takes place by way of the second pathway observed which was enhanced by dilution with nitrogen, and was the only pathway observed upon irradiation at $\lambda>290 \mathrm{~nm}$.

Interconversion of 2,5-dimethylpyridine $\mathbf{1 3}$ with 2,3-dimethylpyridine 14 can be viewed as a reversible 1,3shift of the methyl group from ring position 3 in $\mathbf{1 3}$ to position 5 in 14. A mechanism involving interconverting Dewar-pyridine intermediates is consistent with this regiospecificity. Thus, as shown in Scheme 13, 3,6bonding in the excited state of 2,5-dimethylpyridine 13 would result in Dewar-pyridine DP-13-3,6. A 1,3-shift of nitrogen from $C_{6}$ to $C_{4}$ (Path A) would yield Dewar-pyridine DP-13-3,6 which would rearomatize to the reactant 17 with interchange of ring atoms 4 and 6 . Thus, Path $A$ would be a hidden transition. 1,3-shift of $C_{2}$ to $C_{5}$ (Path B) would lead to DP-14-2,5 and after rearomatization to 2,3-dimethylpyridine 14, the inter-triad product. 

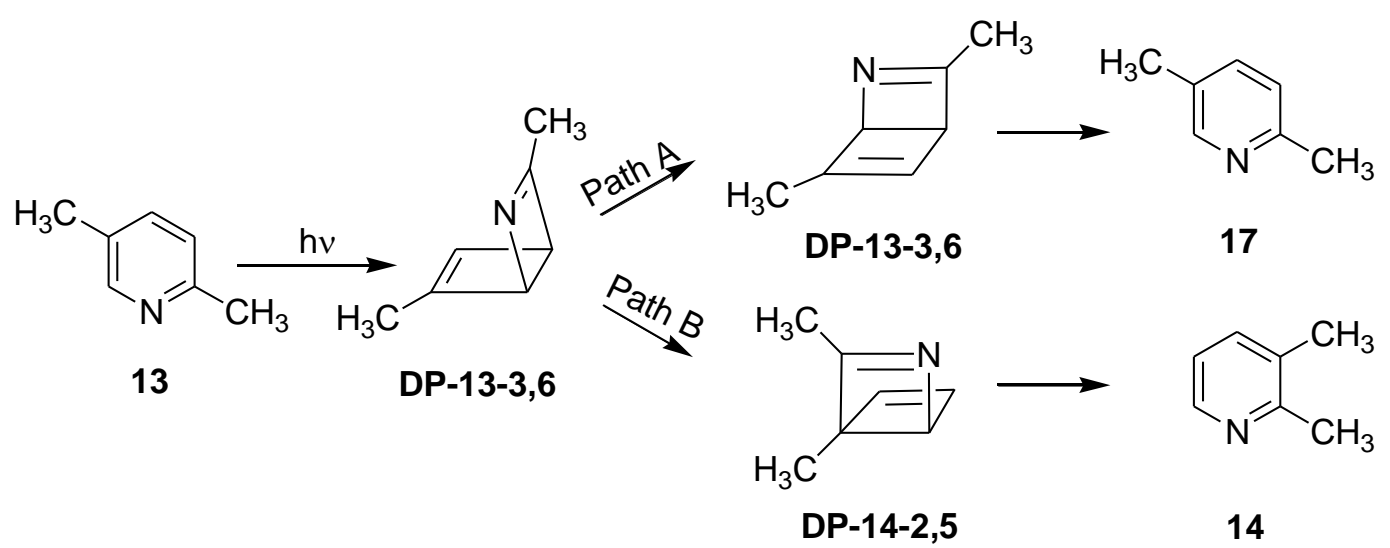

Scheme 13. Mechanism for inter-triad interconversion of 13 and 14. Reprinted with permission. ${ }^{8}$ Copyright 1999, American Chemical Society.

Interestingly, when 2,5-dimethylpyridine 13 or 2,3-dimethylpyridine 14 was irradiated in $\mathrm{CD}_{3} \mathrm{CN}$ at $-30{ }^{\circ} \mathrm{C}$, ${ }^{1} \mathrm{H}-\mathrm{NMR}$ spectroscopy at $-30{ }^{\circ} \mathrm{C}$ showed the formation of Dewar-pyridine DP-13-3,6 or DP-14-2,5.

$\underset{\mathrm{CH}_{3}}{\stackrel{\mathrm{CD}}{\mathrm{CD}_{3} \mathrm{CN},-30^{\circ} \mathrm{C}}}$ 13

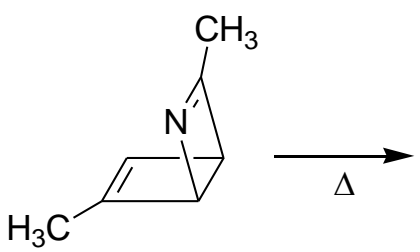

DP-13-3,6<smiles>Cc1cccnc1C</smiles>

14<smiles>Cc1ccnc(C)c1</smiles>

12<smiles>Cc1cncc(C)c1</smiles>

11

Scheme 14. Low temperature irradiation of 13. Reprinted with permission. ${ }^{8}$ Copyright 1999, American Chemical Society.

When the solution was allowed to warm to room temperature, GLC analysis (Scheme 14) showed the formation of 2,3-dimethylpyridine 14, the inter-triad product as the major product, and to much lower yields of 12 and 11 the intra-triad products.<smiles>Cc1cccnc1C</smiles>

14

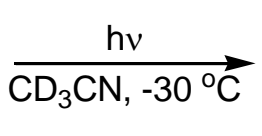

DP-14-3,6

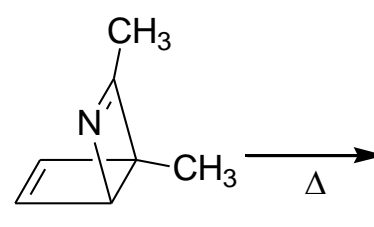

Scheme 15. Low temperature irradiation of 14. Reprinted with permission. ${ }^{8}$ Copyright 1999, American Chemical Society.

When the solution of DP-14-3,6 was allowed to warm to room temperature, GLC analysis showed the formation of 2,5-dimethylpyridine 13, the inter-triad product, as the only transposition product (Scheme 15). 


\subsection{Monosubstituted pyridines: methyl and cyanopyridines}

These studies were extended to the photochemistry of monomethyl and monocyano substituted pyridines in the vapor phase. ${ }^{10}$ It was observed that the three isomers of each compound constitute a photochemical triad. Thus, irradiation of each methylpyridine or each cyanopyridine in the vapor phase at $254 \mathrm{~nm}$ resulted in the formation of the other two isomers as primary products.

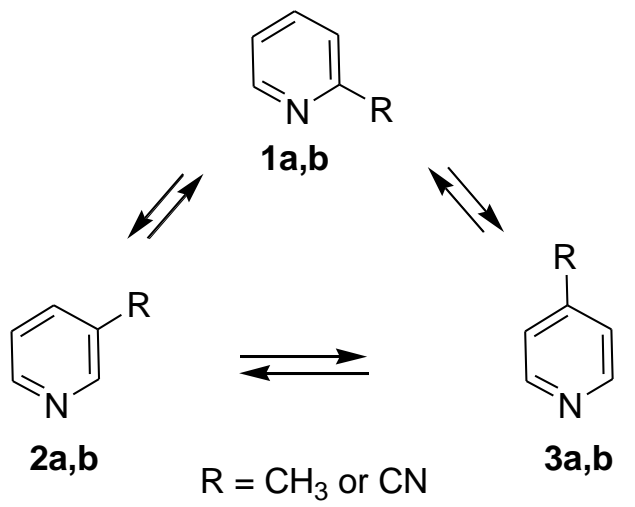

Scheme 16. Photochemical triads from irradiation of monomethyl or monocyanopyridines.

These interconversion are consistent with the 2,6-bonding, nitrogen migration, and rearomaization used to explain the phototransposition chemistry of dimethylpyridines.

Inspection of the mechanism in Scheme 17 shows that 2,6-photocyclization of $\mathbf{1 a , b}$ results in the formation of azaprefulvene BC-1a,b. N-migration in a counter clockwise direction converts $\mathbf{B C}-\mathbf{1} \mathbf{a}, \mathbf{b}$ to $\mathbf{B C}-\mathbf{1} \mathbf{a}, \mathbf{b}$, which would rearomatize back to $\mathbf{1 a}, \mathbf{b}$. This would be an energy wasting process. N-Migration in the clockwise direction, however, leads to $\mathbf{B C}-\mathbf{2} \mathbf{a}, \mathbf{b}$, the precursor of 3 -substituted pyridines $\mathbf{2} \mathbf{a}, \mathbf{b}$.

Inspection of Scheme 17 shows that 3-substituted pyridines $\mathbf{2} \mathbf{a}, \mathbf{b}$ can be from 2 -substituted $\mathbf{1} \mathbf{a}, \mathbf{b}$ by either the one N-migration pathway, $\mathbf{1} \mathbf{a}, \mathbf{b}+\mathbf{h} v$ to $\mathbf{B C}-\mathbf{1} \mathbf{a}, \mathbf{b}$ to $\mathbf{B C}-\mathbf{2} \mathbf{a}, \mathbf{b}$ to $\mathbf{2} \mathbf{a}, \mathbf{b}$, or the two N-migration pathway, $\mathbf{1} \mathbf{a}, \mathbf{b}$ $+h v$ to $\mathbf{B C}-\mathbf{1} \mathbf{a}, \mathbf{b}$ to $\mathbf{B C}-\mathbf{1} \mathbf{\prime} \mathbf{a}, \mathbf{b}$ to $\mathbf{B C}-\mathbf{2} \mathbf{a} \mathbf{a}, \mathbf{b}$ to $\mathbf{2} \mathbf{a}, \mathbf{b}$. Furthermore, conversion of $\mathbf{1} \mathbf{a}, \mathbf{b}$ to the $\mathbf{4}$-substituted $\mathbf{3} \mathbf{a}, \mathbf{b}$ cannot occur via the one $\mathrm{N}$-migration pathway but requires either two $\mathrm{N}$-migrations, $\mathbf{1} \mathbf{a}, \mathbf{b}+\mathrm{h} v$ to $\mathbf{B C}-\mathbf{1} \mathbf{a}, \mathbf{b}$ to $\mathbf{B C}-\mathbf{2} \mathbf{a}, \mathbf{b}$ to $\mathbf{B C}-\mathbf{3} \mathbf{a}, \mathbf{b}$ to $\mathbf{3} \mathbf{a}, \mathbf{b}$ or the three N-migration pathway $\mathbf{1} \mathbf{a}, \mathbf{b}+\mathbf{h} v$ to $\mathbf{B C}-\mathbf{1} \mathbf{a}, \mathbf{b}$ to $\mathbf{B C}-\mathbf{1}^{\prime} \mathbf{a}, \mathbf{b}$ to $\mathbf{B C}-\mathbf{2}^{\prime} \mathbf{a}, \mathbf{b}$ to $\mathbf{B C}-\mathbf{3} \mathbf{a}, \mathbf{b}$ to $\mathbf{3} \mathbf{a}, \mathbf{b}$. Thus it was impossible to determine whether the observed 3-substituted pyridines were formed by one or two N-migration or whether the observed 4-substitutd pyridine were formed from $1 \mathbf{a , b}$ by two or three $\mathrm{N}$-migrations.

In order the explore these possibilities the phototransposition chemistry of $\mathbf{1} \mathbf{a}-\mathbf{4}, \mathbf{6}-\mathbf{d}_{\mathbf{2}}$ was investigated in the vapor phase (Scheme 18). ${ }^{11}$ Deuterium isotope effects were not investigated in this study. ${ }^{1} \mathrm{H}-\mathrm{NMR}$ analysis of the condensed product shows that irradiation of the $\mathbf{1} \mathbf{a}-\mathbf{4}, \mathbf{6}-\mathbf{d}_{\mathbf{2}}$ led to the formation of four products in similar yields after 24 hours of irradiation. 


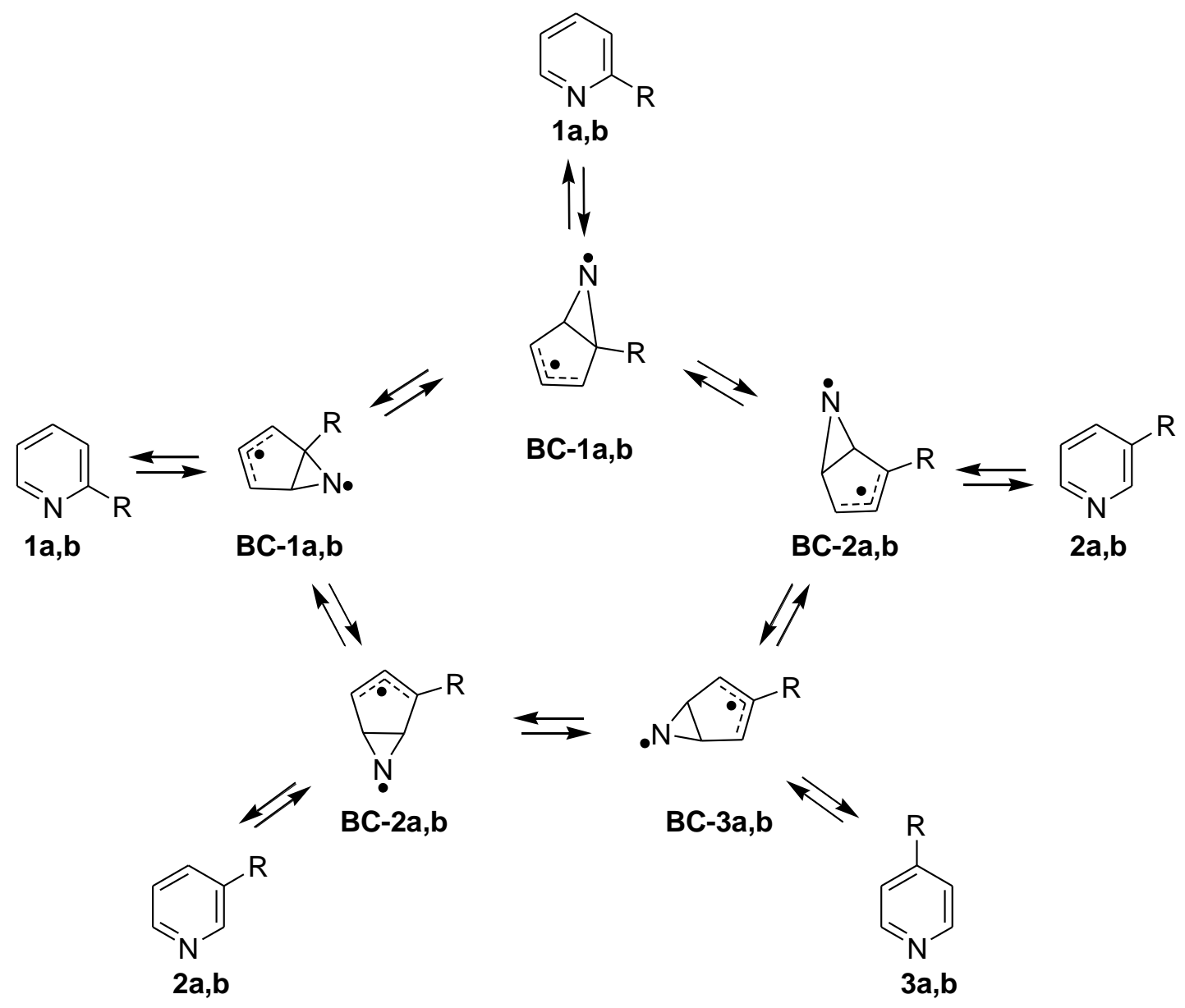

Scheme 17. Phototransposition mechanism for mono-substituted pyridines. Reprinted with permission. ${ }^{10}$ Copyright 2008, American Chemical Society.<smiles>[2H]c1cc([2H])nc(C)c1</smiles>

1a-4,6-d ${ }_{2}$<smiles>[2H]c1cnc(C)c([2H])c1</smiles>

$1 \mathrm{a}-3,5-d_{2}$<smiles>[2H]c1cc([2H])c(C)cn1</smiles>

$2 a-4,6-d_{2}$<smiles>[2H]c1cnc([2H])c(C)c1</smiles>

$2 a-2,5-d_{2}$<smiles>[2H]c1cc(C)c([2H])cn1</smiles>

$3 a-2,5-d_{2}$

Scheme 18. Phototransposition of $1 a-4,5-d_{2}$.

Thus, dideuteration of the ring has expanded the triad to a pentad. Irradiation and analyses as a function

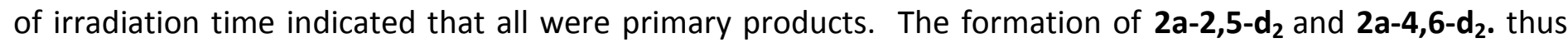
confirms that 3-methylpyridine is formed from 2-methylpyrdine by both the one $\mathrm{N}$-migration and two $\mathrm{N}$ migration pathways.<smiles>[2H]c1ccc(C#N)c([2H])n1</smiles>

$2 b-2,6-d_{2}$<smiles>[2H]c1cncc(C#N)c1[2H]</smiles>

2b-d,5-d 2<smiles>[2H]c1ccnc(C#N)c1[2H]</smiles>

$1 b-3,4-d_{2}$<smiles>[2H]c1ccc([N+]#N)nc1[2H]</smiles>

$1 b-5,6-d_{2}$<smiles>[2H]c1nccc(C#N)c1[2H]</smiles>

$3 b-2,3-d_{2}$

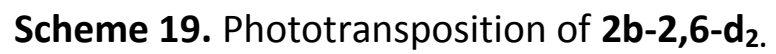


Comparison of the irradiation times for 3-methylpyridine and 3-cyanopyridine showed that the latter is substantially less reactive. Interestingly, ${ }^{1} \mathrm{H}-\mathrm{NMR}$ analysis of the condensed product from the irradiation of 3cyanopyridine-2,6- $\mathbf{d}_{2} \mathbf{2} \mathbf{b}-\mathbf{2}, \mathbf{6}-\mathbf{d}_{\mathbf{2}}{ }^{12}$ (Scheme 19 ) showed that the major product was 3-cyanopyridine-4,5- $\mathbf{d}_{2} \mathbf{2} \mathbf{b}-$ $\mathbf{4 , 5}-\mathbf{d}_{\mathbf{2}}$. Since this transposition would not be observed in the absence of the deuterium labels, this explains why undeuterated 3-cyanopyridine $\mathbf{2 b}$ appears to be unreactive. Other minor products observed were 2cyanopyridine-3,4- $d_{2} \mathbf{1 b}-\mathbf{3}, \mathbf{4}-\mathbf{d}_{\mathbf{2}}$, 2-cyanopyridine-5,6- $\mathrm{d}_{2} \mathbf{1} \mathbf{b}-\mathbf{5}, \mathbf{6}-\mathbf{d}_{\mathbf{2}}$ and 4-cyanopyridine-2,3- $\mathrm{d}_{2} \mathbf{3} \mathbf{b}-\mathbf{2}, \mathbf{3}-\mathbf{d}_{\mathbf{2}}$.

Examination of Scheme 20 shows that the conversion of $\mathbf{2} \mathbf{b}-\mathbf{2}, \mathbf{6}-\mathbf{d}_{\mathbf{2}}$ to $\mathbf{2} \mathbf{b}-\mathbf{4}, \mathbf{5}-\mathbf{d}_{\mathbf{2}}$ requires the two $\mathrm{N}$ -

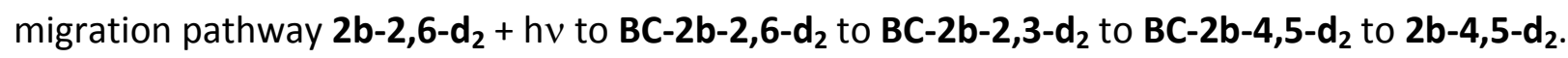

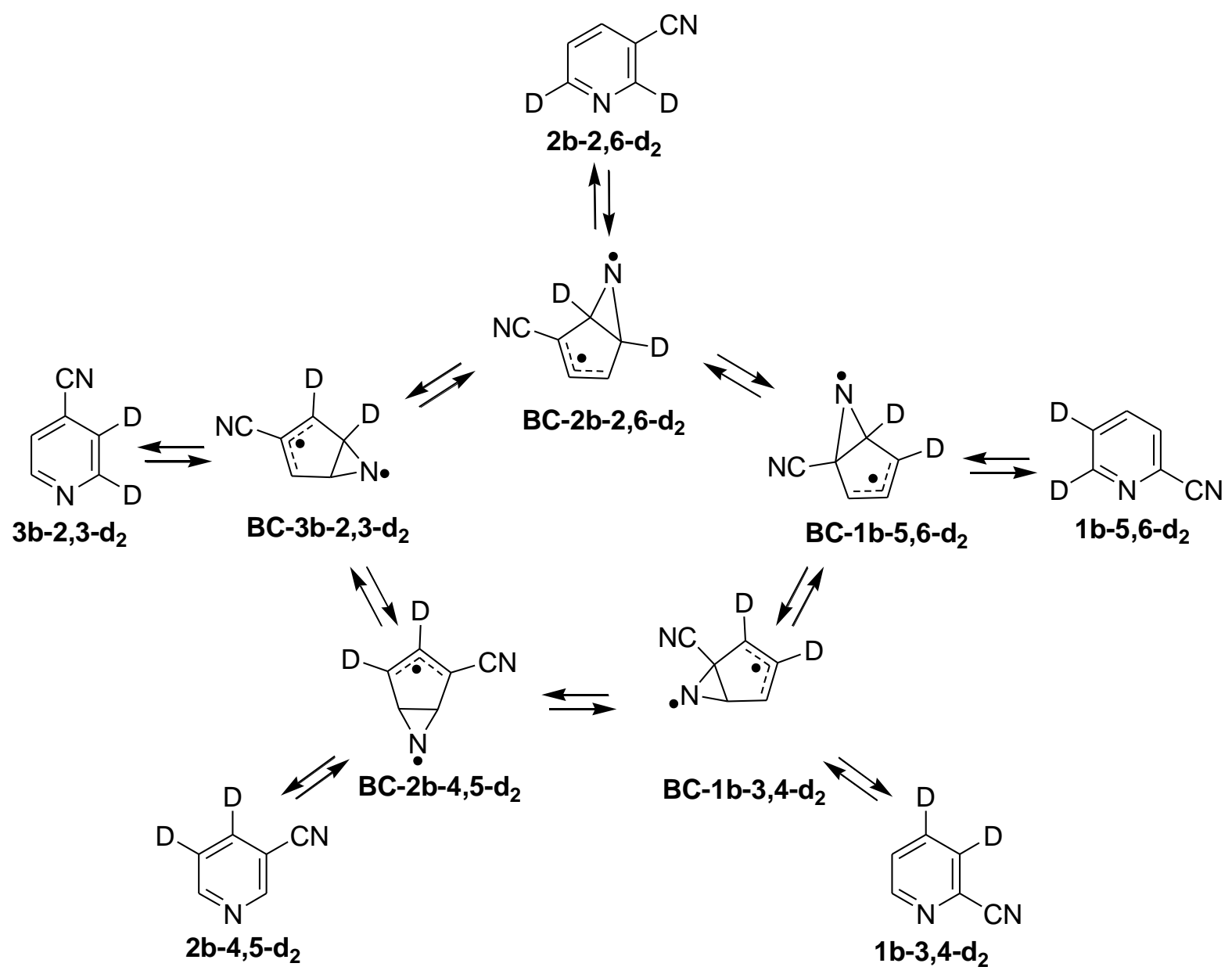

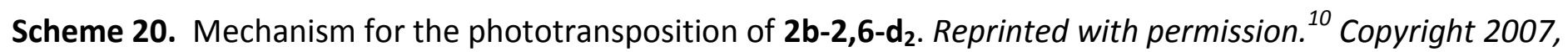
American Chemical Society.

Indeed, because of the stabilizing effect of the cyano group at the end of the allyl system in $\mathbf{B C}-\mathbf{2} \mathbf{b}-\mathbf{4}, \mathbf{5}-\mathbf{d}_{\mathbf{2}}$, this is major pathway. Since both $\mathbf{1} \mathbf{b}-\mathbf{5}, \mathbf{6}-\mathbf{d}_{\mathbf{2}}$ and $\mathbf{1 b}-\mathbf{3}, \mathbf{4}-\mathbf{d}_{\mathbf{2}}$ were formed from $\mathbf{2} \mathbf{b}-\mathbf{2}, \mathbf{6}-\mathbf{d}_{\mathbf{2}}$, both one N-migration and two N-migration pathways are implicated.

Because of the symmetry of 4-trideuteromethylpyridine-2,6- $d_{2}\left(3 a-2,6-d_{2}\right)$, the transformation remains a

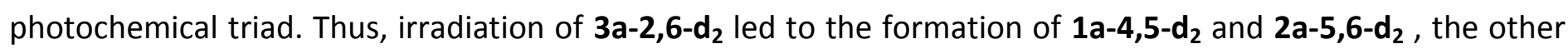
two members of the triad (Scheme 21 ) in essentially equal yields. 


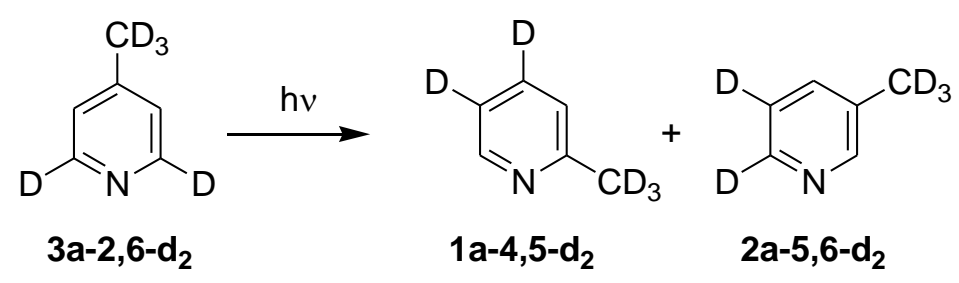

Scheme 21. Phototransposition of 3a-2,6-d $\mathbf{2}$.

This symmetry was removed by synthesizing and irradiating 4-trideutero-2,3,5- $d_{3}\left(3 a-2,3,5-d_{3}\right)$. After

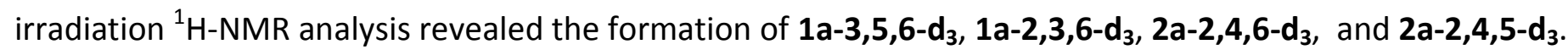<smiles>[2H]c1cnc([2H])c(C([2H])([2H])[2H])c1[2H]</smiles>

$3 a-2,3,5-d_{3}$<smiles>[2H]c1cc([2H])c(C([2H])([2H])[2H])nc1[2H]</smiles>
$1 \mathrm{a}-3,5,6-\mathrm{d}_{3}$<smiles>[2H]c1cc([2H])c([2H])c(C([2H])([2H])[O-])n1</smiles>

$2 a-2,4,6-d_{3}$<smiles>[2H]c1cnc([2H])c(C([2H])([2H])[2H])c1[2H]</smiles>

$2 a-2,4,5-d_{3}$

Scheme 22. Phototransposition of $3 a-2,3,5-d_{3}$.

These results confirm that when the symmetry of the molecule is removed the triad is expanded to a pentad.

\subsection{Deuterated pyridines}

In order to minimize the effect of substituents on the pyridine ring a series of trideuterated and tetradeuterated pyridines were synthesized ${ }^{13}$ and studied. $^{14}$ It was observed that the six isomeric trideuterated pyridines can be divided into two photochemical triads (Scheme 23). Triad 1 consists of 4-3,4,5-

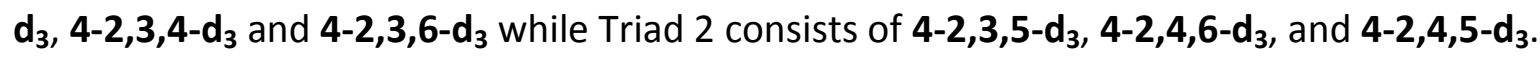

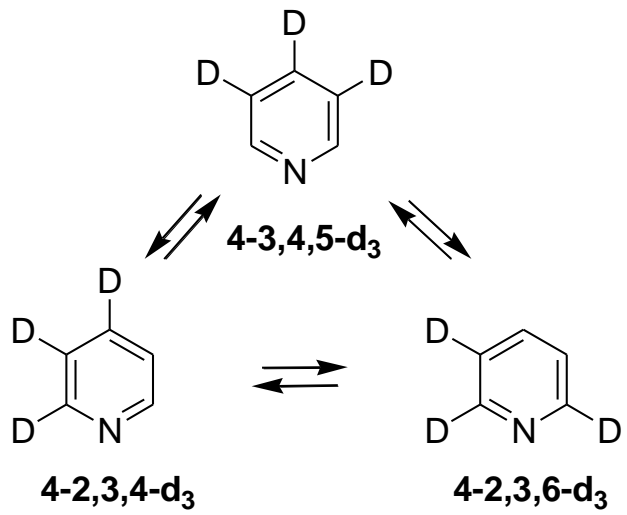

Triad 1

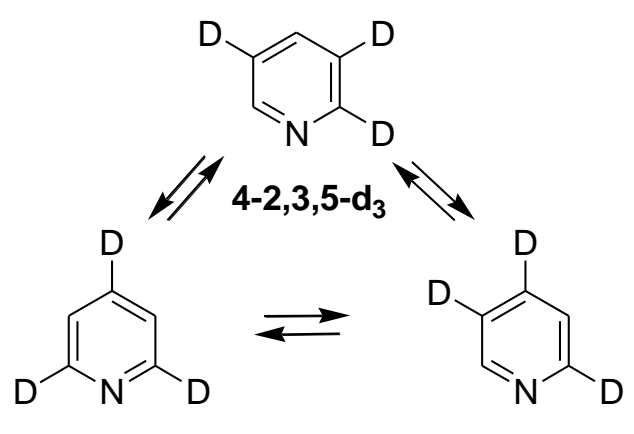

$4-2,4,6-d_{3}$

Triad 2

Scheme 23. Two photochemical triads of the trideuterated pyridines. Reprinted with permission. ${ }^{14}$ Copyright 2008, American Chemical Society. 
The photochemistry of these six pyridines each bearing two ring hydrogen is almost identical to the photochemistry of the six isomeric dimethylpyridines. ${ }^{8}$ In that case, the six isomers could also be divided into triads of three interconverting compounds. Although the case of the dimethylpyridines a linkage between the two triad was observed, in the case of the trideuteropyridines, no interconversion of any member of triad 1 with any member of triad 2 was observed. ${ }^{15}$

The three isomeric tetradeuterated pyridine isomers were also synthesized ${ }^{13}$ and their vapor phase photochemistry studied. Upon irradiation, each of the three isomeric tetradeuteropyridines was observed to undergo phototransposition leading to the other two isomers.

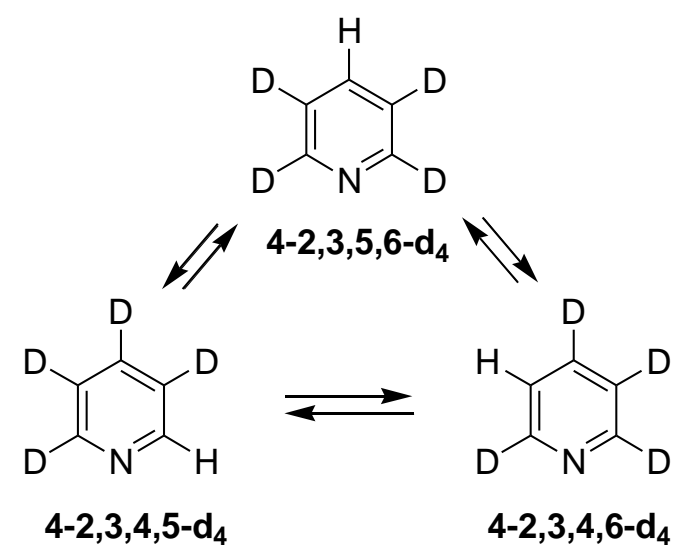

Scheme 24. Photochemical triad of tetradeuteropyridines. Reprinted with permission. ${ }^{14}$ Copyright 2008, American Chemical Society.

These three pyridines bearing one ring hydrogen, constitute a photochemical triad (Scheme 24) and are analogues to the monosubstituted methyl and cyanopyridines.

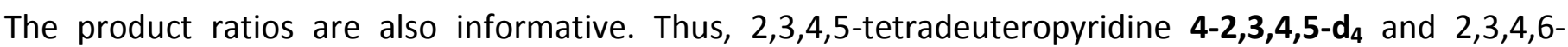

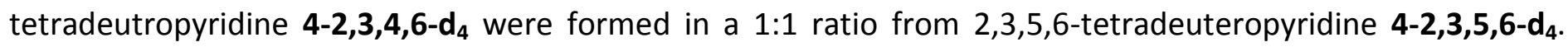

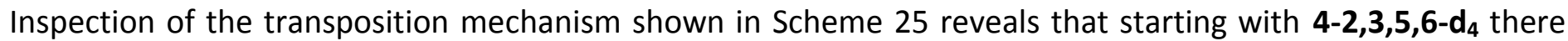
are an equal number of ways that the two products can be formed. This is consistent with their formation in a $1: 1$ ratio.

In contrast, , Scheme 25 shows that starting with 4-2,3,4,6- $\mathbf{d}_{\mathbf{4}}$ there are two pathways leading to 4-2,3,4,6-

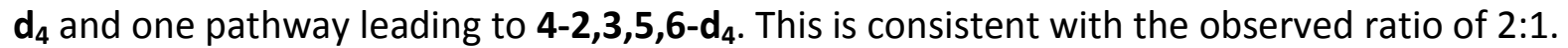

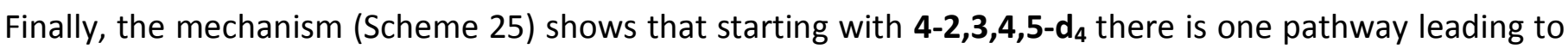

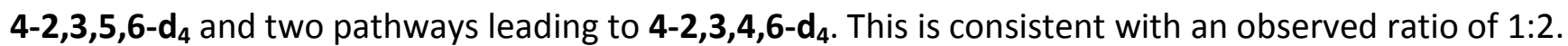




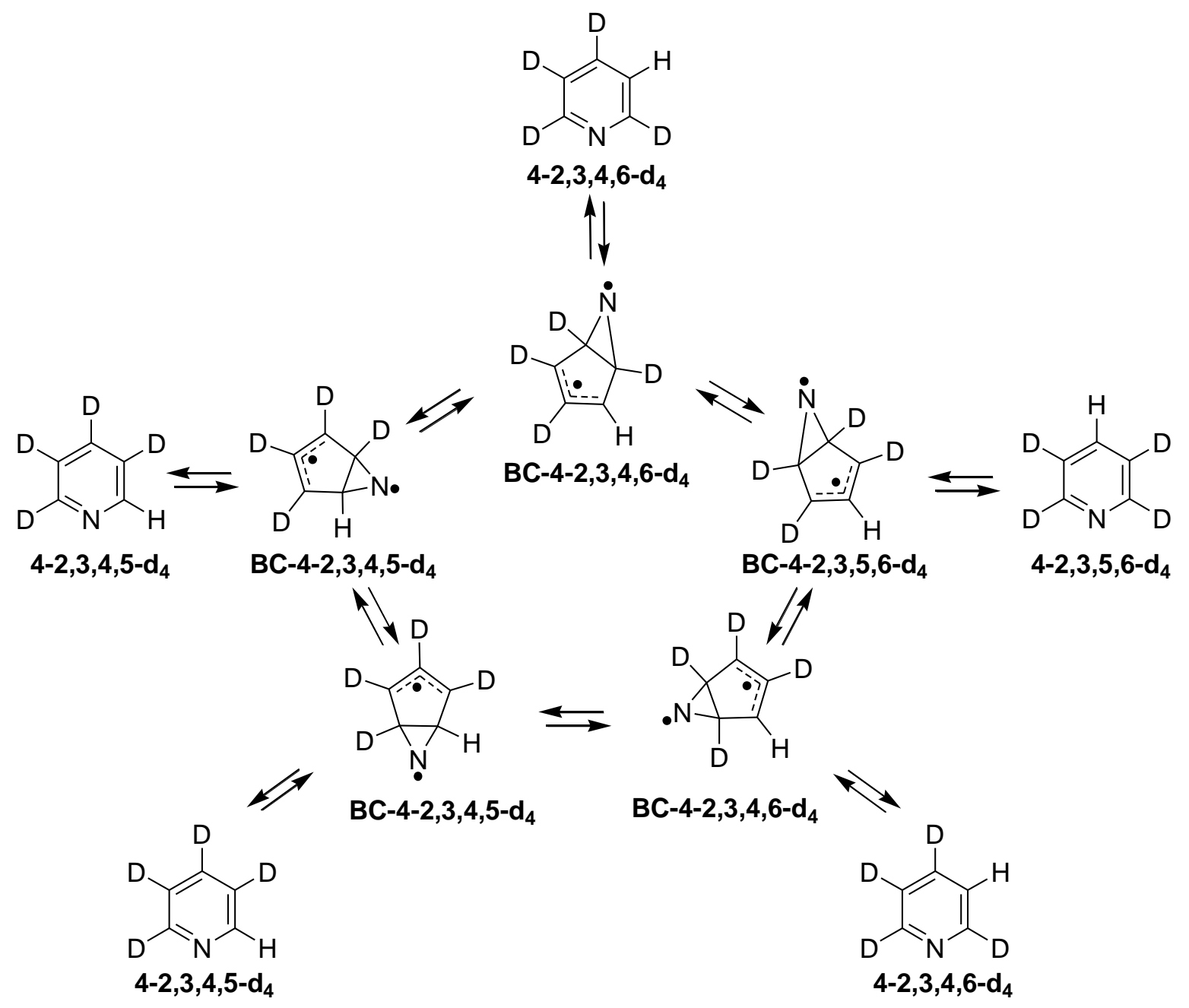

Scheme 25. Transposition mechanism for tetradeuteropyridines. Reprinted with permission. ${ }^{14}$ Copyright 2008, American Chemical Society.

\subsection{Mechanistic discussion}

The energies of the $S_{1}\left(n, \pi^{*}\right)$ and $S_{2}\left(\pi, \pi^{*}\right)$ states in 2,6-dimethylpyridine 20 are 100.4 and $105.5 \mathrm{kcal} \mathrm{mol}^{-1}$, and the six dimethylpyridines are expected to have similar excited state-energies. ${ }^{16}$ Irradiation of dimethylpyridines with light of $254 \mathrm{~nm}$ is expected to result the population of $S_{2}\left(\pi, \pi^{*}\right)$ with excess vibrational energy.

The non-radiative decay properties of pyridines are reported to be dependent on this excess vibrational energy. Thus, the $\phi_{f}$ in pyridine shows a dependence on the excited vibrational energy in the lowest $\pi$ - $\pi *$ excited state. ${ }^{16-18}$ The sudden decrease in $\phi_{f}$ suggests the existence of a decay channel known as channel three. ${ }^{19-24}$ In benzene, this decay pathway leads to the formation of the ground-state diradical prefulvene, the presumed precursor benzvalene. ${ }^{9}$

In pyridine theoretical calculations predict that the $S_{2}\left(\pi, \pi^{*}\right)$ state of pyridine crosses both the $S_{1}\left(n, \pi^{*}\right)$ and $S_{0}$ states along a concerted pathway leading to ground-state azaprefulvene diradical, the suggested intermediate responsible for the intra-triad isomerization. ${ }^{25}$ Quenching of these intra-triad reaction by added $\mathrm{N}_{2}$ is consistent with their origin from an excited state possessing excess vibrational energy. 
On the basis of femtosecond absorption studies and theoretical calculations, ${ }^{26}$ Zewail and Chachovillis have shown that in solution, the $S_{2}\left(\pi, \pi^{*}\right)$ state of pyridine can readily pass over a low energy-barrier and through a conical intersection to yield the azaprefulvene species which has a lifetime of greater than 2 ns. Apparently this is enough time for nitrogen to migrate around the sides of cyclopentadienyl ring.

\section{Conclusions}

Early work reported that irradiation of pyridine in the vapor phase at $254 \mathrm{~nm}$ resulted only in decomposition. No identified products were detected. Later it was discovered that pyridine vapor undergoes phototransposition upon irradiation. These reactions involve the interchange of ring carbon atoms in the pyridine molecules. Thus, in the absence of labels at the ring carbons, these reactions would not be observed.

\section{Acknowledgements}

The authors wish to thank the Department of Chemistry and Biochemistry at Worcester Polytechnic Institute and Edinboro University for their support of this research.

\section{References and Notes}

1. Pavlik, J. W. In CRC Handbook of Organic Photochemistry and Photobiology, $2^{\text {nd }}$ ed. Horspool, W. M., Lenci, F. (eds.) CRC Press, Boca Raton, FL, 2004, Chapter 97, 1-22.

2. Pascual, O. L.; Tuazon, L. O. Philippines Nucl. J. 1966, 49-51. Chem. Abs. 1967, 66, 115125b.

3. Linnel, R. H.; Noyes, W. A. J. Am. Chem. Soc., 1951, 73, 3986-3988.

https://doi.org/10.1021/ja01152a126

4. Noyes, W. A.; Al-Ani, K. Chem. Rev. 1974, 74, 29-43.

https://doi.org/10.1021/cr60287a003

5. Robeke, W. J. Phys. Chem. 1970, 74, 4198-4203.

https://doi.org/10.1021/i100718a004

6. Caplain, S.; Lablanche-Combier, A. J. Chem. Soc. Chem. Commun. 1970, 1247-1248. https://doi.org/10.1039/c29700001247

7. Dewar, M. J. S. J. Chem. Res. 1978, 26-27.

8. Pavlik. J. W.; Kebede, N.; Thompson, M.; Day, A. C.; Barltrop, J. A. J. Am. Chem. Soc., 1999, 121, 5666-5673. https://doi.org/10.1021/ja990773r

9. Bryce-Smith,D ; Longuet-Higgins, H.C. Chem. Commun. 1966, 593-594.

https://doi.org/10.1039/c19660000593

10. Pavlik, J. W.; Laohhasurayotin, S.; Vongnakorn, T. J. Org. Chem. 2007, 72, 7116-7124.

https://doi.org/10.1021/jo070810u

11. Pavlik, J. W. ; Vongnakorn, T. ; Tantayanon, T. J. Heterocylic Chem. 2009, 46, 213-216.

https://doi.org/10.1002/jhet.55

12. Pavlik, J. W.; Laohhasurayotin, S. J. Heterocyclic Chem. 2005, 42, 73-76.

https://doi.org/10.1002/jhet.5570420110

13. Pavlik, J. W.; Laohhasurayotin, S. J. Heterocyclic Chem. 2007, 44, 1485-1492. 


\section{https://doi.org/10.1002/jhet.5570440637}

14. Pavlik, J.W.; Laohhasurayotin, J. Org. Chem. 2008, 73, 2746-2752.

\section{https://doi.org/10.1021/jo7026799}

15. In this study, since product mixtures could not be analyzed by GLC, small amount of leakage product would be difficult to detect.

16. Yamazaki, I.; Sushida, K.; Baba, H. J Phys. Chem. 1979, 381-387.

https://doi.org/10.1063/1.438081

17. Yamazaki, I.; Sushida, K.; Baba, H, J. Lumin. 1979, 424-428.

18. Yamazaki, I.; Murao, T.; Yamanaka, T.; Yoshibara, K. Faraday Discuss. Chem. Soc. 1983, 75, 395-405. https://doi.org/10.1039/dc9837500395

19. Riedle, E.; Weber, T.; Shubert, U. ; Neusser, H. J.; Schlag, E. W. J. Chem. Phys. 1990, 95, 967-978. https://doi.org/10.1063/1.459123

20. Suzuki, T.; Ito, M. J. Chem. Phys. 1989, 91, 4564-4570.

https://doi.org/10.1063/1.457635

21. Hornburger, H.; Sharp, C. M. Chem. Phys. 1989, 101, 67-79.

https://doi.org/10.1016/0301-0104(86)87023-9

22. Sobolewski, A.G .; Czerminski, R. Chem. Phys. 1984, 130, 123-128.

https://doi.org/10.1016/0301-0104(89)87041-7

23. Sobolewski, A. G. J. Chem. Phys. 1990, 93, 6433-6439.

\section{https://doi.org/10.1063/1.458959}

24. Sobolewski, A. G.; Lim, E. C.; Siebtana, W. Int. J. Quantum. Chem. 1991, 39, 309-324.

https://doi.org/10.1002/qua.560390309

25. Sobolewski, A. G.; Domcke, W. Chem. Phys. Lett. 1991, 180, 381-386.

https://doi.org/10.1016/0009-2614(91)90337-9

26. Chachisvlis, M. Zewail, A. H. J. Phys. Chem. A. 1999, 103, 7408-7418.

\section{Authors' Biographies}

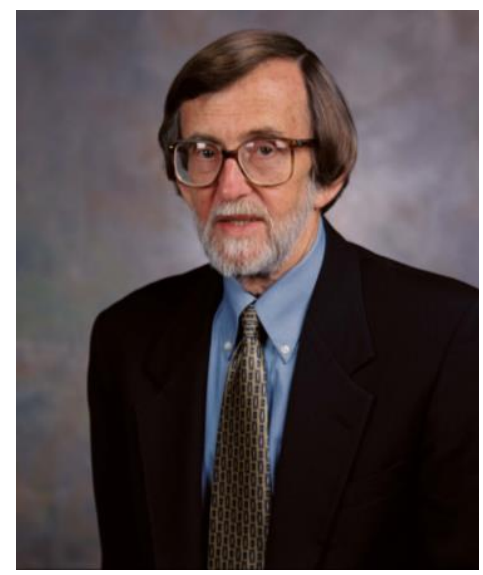

Dr. James W. Pavlik was born in Chicago, Illinois, USA in 1937. He graduated from Carthage College in 1959 and received his Ph.D. in chemistry in 1970 from The George Washington University under the supervision of Professor Nicolae Filipsecus. After brief academic appointments in Ghana, Ethiopia, and the University of Wisconsin-RF he joined the faculty of the Department of Chemistry and Biochemistry at Worcester Polytechnic 
Institute in 1974. He was promoted to Professor of Chemistry in 1980 and served as Head of the Department for 17 years before he retired in 2009. His research has focused on the photochemistry of heteroaromatic compounds in solution and in the gas phase. He published 70 research papers and 7 book chapters. He is a member of the American Chemical Society.

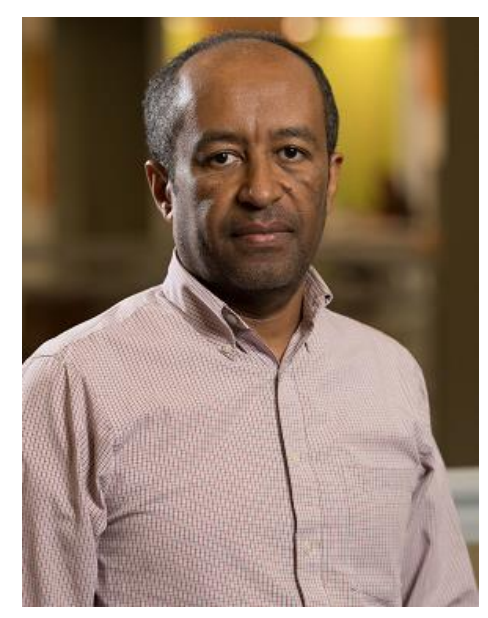

Dr. Naod Kebede was born in Addis Ababa, Ethiopia in 1965. He graduated from Addis Ababa University in 1986 and received an M.S. in Eremology in 1993 from Gent University, Gent, Belgium under the supervision of Prof. Ir. F. Lambein, and Ph.D. in Chemistry in 1998 from Worcester Polytechnic Institute under the supervision of Prof. James W. Pavlik followed by a postdoctoral fellowship at the Johns Hopkins University under the supervision of Prof. J. P. Toscano. He Joined Edinboro University in 2000 and was promoted to Professor in 2009. His research interest are photochemistry of heteroaromatic compounds, computational chemistry and chemical analysis. He is a member of the American Chemical Society, the American Association for the Advancement of Science and the Inter-American Photochemical Society. 